\title{
REPOSITÓRIO INSTITUCIONAL EM COMUNICAÇÃO: o projeto Reposcom implementado junto à Federação de Bibliotecas Digitais em Ciências da Comunicação ${ }^{1}$ \\ INSTITUTIONAL REPOSITORY IN COMMUNICATION: the Reposcom \\ Project implemented in the Digital Libraries Federation of \\ Communication Science.
}

Sueli Mara Soares Pinto Ferreira Livre Docente e Doutora em Ciências da Comunicação Professora do Programa de Pós-graduação em Ciência da Informação da ECA/USP Coordenadora da Portcom - Rede de Informação em Ciências da Comunicação dos Países de Língua Portuguesa. smferrei@usp.br

Comente este artigo no blog Ebibli = http://encontros-bibli-blog.blogspot.com/

\section{RESUMO}

Partindo do conceito, caracterização, entorno e contexto dos repositórios institucionais (RI), este artigo discute os procedimentos, políticas e estratégias definidas para sua implementação em um ambiente de pesquisa. Trata-se do Reposcom - Repositório Institucional da Intercom - Sociedade Brasileira de Estudos Interdisciplinares da Comunicação, que está inserido em um projeto maior intitulado "Federação de Bibliotecas Digitais em Ciências da Comunicação" desenvolvido pela Portcom - Rede de Informação em Ciências da Comunicação dos Países de Língua Portuguesa. Com o objetivo de compartilhar os conhecimentos obtidos descrevem-se as etapas de trabalho, as decisões tomadas e os resultados obtidos com sua implementação e com a customização do software DSpace, selecionado para dar o suporte tecnológico necessário. Conclui apresentando os desdobramentos futuros ainda por vir desse projeto.

Palavras-chave: Repositórios Institucionais. Software DSpace. Federação de Bibliotecas Digitais. Ciências da Comunicação. Comunicação científica. Iniciativa do Acesso Livre.

\section{AS COMUNIDADES ACADÊMICAS E OS PROCESSOS PARA A ELABORAÇÃO, DISSEMINAÇÃO E GESTÃO DE SUA PRODUÇÃO CIENTÍFICA.}

A introdução das TICs - tecnologias de informação e comunicação, no meio acadêmico, tem provocado uma expressiva mudança na comunicação entre pesquisadores e cientistas, sobretudo no que se refere à publicação, disseminação e compartilhamento dos resultados de pesquisas - atividades consideradas vitais para a formalização da "comunicação científica".

Certamente, a publicação de textos científicos foi a primeira prova concreta dessa mudança, comprovada pela migração das publicações impressas para as

\footnotetext{
${ }^{1}$ Esse artigo apresenta parte dos resultados divulgados na tese de livre docência defendida em novembro de 2006, junto à Escola de Comunicações e Artes da USP, na linha Geração e Uso da Informação.
} 
eletrônicas, em particular para as revistas eletrônicas. A busca por fluxos de comunicação científica mais eficientes, econômicos e transparentes levou a comunidade a adotar novas formas para publicar seus produtos científicos a partir do domínio de uma tecnologia própria.

Neste contexto, esta comunidade se vê frente à possibilidade de sanar sua necessidade mais básica no que se refere ao acesso, à disseminação, ao compartilhamento e ao uso do conhecimento global e local, por meio de espaços específicos, públicos, qualificados e integrados. Para tanto, está lhe sendo exigido: (a) conhecimento, posicionamento e atitude frente a temas como acesso público à informação, preservação digital, direitos autorais, auto-arquivamento, publicação eletrônica, dentre outros; (b) controle de mecanismos de gestão de conteúdo padronizado internacionalmente, e (c) disponibilidade para trabalho cooperativo e integrado.

As bibliotecas digitais surgem como alternativa para atender tais questões. Compreendidas sob dois pontos de vistas - como sistemas de informação sócio-técnicos (compostos por tecnologias, informações, documentos, pessoas e práticas (BISHOP, VAN HOUSE e BUTTENFIELD, 2003)) e sob o ponto de vista operacional (como coleções organizadas de informação digital), elas combinam estrutura e conjunto de informação de bibliotecas e arquivos, com a representação digital que os computadores tornaram possível (LESK, 1997 apud PINHEIRO, 2002).

Seu inegável papel nas atividades de gerenciamento da produção científica, preservação digital, acesso e recuperação de informação e sua expertise e vocação no que tange ao desenvolvimento de competências informacionais em sua clientela foram logo aprimorados por outra possibilidade - a Federação de Bibliotecas Digitais ${ }^{2}$. Uma Federação agrega a possibilidade de compartilhar e interoperar, de maneira mais efetiva, conhecimentos gerados e armazenados em locais distintos, heterogêneos, dispersos e em várias plataformas.

Segundo Pirri et al (2002) e Gonçalves, France e Fox (2001) uma Federação se refere à composição ou união de várias bibliotecas digitais independentes, autônomas ou semi-autônomas, distribuídas na Internet e organizadas por temas ou recursos específicos que formam uma rede de bibliotecas com interface de acesso único e integrado à grande quantidade e heterogeneidade de informação estruturada, semiestruturada e não-estruturada (vídeos, apresentações, imagens, sons, gráficos, etc.).

Contextualiza esse desenvolvimento de bibliotecas digitais e de federações dois relevantes movimentos - o Movimento dos Arquivos Abertos (OAI) ${ }^{3}$ e o Movimento do Acesso Livre $(\mathrm{OA})^{4}$, os quais representam um marco, pois oferecem:

- soluções técnicas efetivas, ágeis, econômicas e viáveis para que comunidades científicas reconstruam práticas e processos de comunicação científica, sistemas de gestão cooperativos, mecanismos de controle bibliográfico, preservação da memória, promovendo assim a consolidação de seu corpus de conhecimento.

\footnotetext{
${ }^{2}$ Maiores informações - FERREIRA e SOUTO, 2006.

${ }^{3}$ Maiores detalhes http://www.openarchives.org/documents/ FAQ.html

${ }^{4}$ Existe uma discussão sobre a melhor tradução para Open Access. Alguns especialistas entendem que o melhor seria Acesso Aberto, outros acham que seria Acesso Livre. Optou-se por utilizar a expressão "acesso livre" que vem sendo adotada pelo IBICT. Por acesso livre entende-se a disponibilização livre, na Internet, de literatura de caráter acadêmico ou científico, permitindo a qualquer pessoa ler, descarregar (download), copiar, distribuir, imprimir, pesquisar ou referenciar (links) o texto integral de documentos (BOAI, 2002). Maiores informações - http://www.ibict.br/openaccess.
} 
- e ainda suporte teórico e filosófico que - perpetuando os princípios clássicos referendados pela comunidade científica (acessibilidade, confiabilidade e publicidade) - possibilitam a discussão sobre a disseminação ampla e irrestrita do conhecimento (principalmente aquele gerado com financiamento público); a necessidade de maior visibilidade; a legitimação e institucionalização de sistemas informais de publicação científica para a revisão das práticas associadas à concessão de seus direitos de autor aos editores comerciais, a transparência no processo de peer-review, compartilhamento público sem custos dentre outras questões.

Como estratégias para atingir tais objetivos, a Declaração de Budapeste Budapest Open Access Initiative (BOAI, 2002) propõe: (a) o auto-arquivamento - que diz respeito ao depósito espontâneo pelo autor dos resultados de seu trabalho em um arquivo digital público e acessível construído com base no protocolo OAI/PMH (Open Archives Initiative/Protocol for Metadata Harvesting $)^{5}$ e um conjunto de procedimentos técnico-operacionais visando o estabelecimento de padrões de interoperabilidade ${ }^{6}$; e, (b) a produção de revistas de acesso público, ou seja, disponível gratuitamente via internet para a comunidade.

Um dos resultados dessas estratégias, em especial aquela voltada aos arquivos digitais, é o surgimento dos chamados repositórios digitais. Repositórios, segundo o Glossário do IBICT (s/d), são sistemas de informação que armazenam, preservam, divulgam e dão acesso à produção intelectual de comunidades científicas. Incentivam e gerenciam a publicação pelo pesquisador (auto-arquivamento), utilizam tecnologia aberta e podem ser acessados por diversos provedores de serviços nacionais e internacionais.

Eles podem ser temáticos - quando colocam o foco em uma determinada área do conhecimento; ou institucionais - quando se constituem em um conjunto de serviços oferecido por uma dada instituição aos membros de sua própria comunidade para a gerência e a disseminação dos materiais digitais criados por ela, ou seja, seu foco é a memória técnica de uma dada instituição que pode ser composta por trabalhos publicados e/ou originais e apresentados em distintos formatos, suportes e tecnologias (LYNCH, 2003).

Conforme proposto por Weitzel (2006), os repositórios podem ser visualizados como readaptações das antigas bibliografias especializadas, ou ainda, dos serviços de indexação e resumo, agora implementados e gerenciados pelas próprias comunidades científicas visando contribuir para:

- o aumento da visibilidade, estatuto, imagem e "valor" público da instituição, servindo como indicador tangível de sua qualidade e demonstrando as relevâncias científicas, econômicas e sociais das suas atividades de pesquisa e ensino;

- a reforma do sistema de comunicação científica, expandindo o acesso aos resultados da pesquisa, reassumindo o controle acadêmico sobre a publicação científica, aumentando competitividade e reduzindo o monopólio das revistas científicas,

\footnotetext{
${ }^{5}$ Trata-se de "um protocolo que estimula a geração de publicações de livre acesso, disseminando a produção científica para acessos locais e global alinhando-se, portanto, aos movimentos dos arquivos abertos, do livre acesso à informação e ao conhecimento em ciências e humanidades", conforme Arellano, Ferreira e Caregnato (2005, p.198). Esta tem sido a base de toda a atual discussão envolvendo interoperabilidade e federação de conteúdos.

${ }^{6}$ Segundo Van de Sompel \& Lagoze (apud SENA, 2000), interoperabilidade "envolve uma série de aspectos, tais como: conjunto mínimo de metadados, tipo de arquitetura subjacente do sistema, abertura para a criação de serviços de bibliotecas digitais de terceiros ou repositórios de eprints, integração com o mecanismo de comunicação já existente no meio científico, possibilidade de uso em contextos interdisciplinares e contribuição para criação de um sistema de medida de uso e de citação".
} 
reorganiza o sustento econômico e aumenta a relevância da instituição e de sua biblioteca (RODRIGUES et all, 2004; CROW, 2002).

Diversas ferramentas tecnológicas vem sendo criadas para a implementação de repositórios institucionais, muitas delas pautadas nas estratégias e princípios já mencionados. De maneira geral, verifica-se o surgimento de ferramentas que possibilitam atuação em duas diferentes frentes:

(a) aquelas que possibilitam a implementação de repositórios que se constituem em espaços de armazenamento, recuperação e preservação da memória técnica produzida em uma dada área ou instituição.

(b) e aquelas voltadas à implementação de repositórios cujo propósito seria a criação de espaços para a construção/reconstrução e compartilhamento do conhecimento visando otimizar a prática e o processo de pesquisa em determinada área. A interação entre autores, nesse modelo, é baseada em comentários espontâneos a respeito do conteúdo dos documentos ali depositados. Portanto, uma ferramenta que ademais de servir aos requisitos descritos no modelo anterior, ainda se insere na discussão sobre a transparência do processo de peer review, motivando a prática de comentários e revisão pública e aberta.

A maioria dos softwares disponíveis atualmente se encaixa no primeiro modelo. Um dos mais utilizados hoje é o DSpace desenvolvido pelo MIT (Massachusetts Institute of Technology, EUA) e HP (Hewlett-Packard, EUA). Outro software bastante conhecido é o Eprints, desenvolvido pela Southampton University, UK, que nasceu com a estrutura de atuação do segundo modelo descrito acima, mas que em sua versão atual (1.3) já não possibilita essa funcionalidade. Uma explicação para a eliminação de tal funcionalidade pode ser a percepção da falta de uso pela comunidade nos vários repositórios instalados com o Eprints. Soma-se a esse fato, os resultados empíricos demonstrados em vários estudos junto a usuários e pesquisadores (SWAN, BROWN, 2005; HARLEY et all, 2006), os quais evidenciam que tal função, embora cobiçada pelos membros da comunidade científica geral, acaba encontrando inúmeros obstáculos na prática, tanto em função da cultura vigente e arraigada ao atual processo milenar de revisão e dos colégios invisíveis, como pela dificuldade pessoal em enfrentar a exposição pública que isso representa.

Este artigo descreve a implementação do Repositório Institucional da Sociedade de Estudos Interdisciplinares da Comunicação / INTERCOM ${ }^{7}$, intitulado Respocom ${ }^{8}$. Esse repositório vem sendo desenvolvido pela Portcom - Rede de Informação em Ciências da Comunicação dos Países de Língua Portuguesa ${ }^{9}$ inserido no projeto da Federação de Bibliotecas Digitais em Ciências da Comunicação ${ }^{10}$. Com o objetivo de compartilhar os conhecimentos obtidos são sintetizadas as etapas de trabalho, as decisões tomadas e os resultados obtidos com sua implementação e com a customização do software DSpace, selecionado para dar o suporte tecnológico necessário.

Visando contextualizar a instituição onde o repositório está instalado e evidenciar sua importância, insere-se inicialmente um breve relato da área de comunicação no país, suas raízes e frutos na Intercom.

\section{CIÊNCIAS DA COMUNICAÇÃO NO BRASIL E A INTERCOM}

\footnotetext{
${ }^{7}$ Maiores informações: http://www.intercom.org.br/

${ }^{8}$ Maiores informações: http://reposcom.portcom.intercom.org.br/

${ }^{9}$ Maiores informações: http://www.portcom.intercom.org.br/

${ }^{10}$ Maiores informações sobre o projeto da Federação - ver FERREIRA e SOUTO, 2005.
} 
A comunicação no Brasil, enquanto uma área de estudos e pesquisa, é entendida por muitos não como uma ciência, mas, sim, como campo de estudo multidisciplinar, cujo método de análise não tem nenhuma especificidade, sendo desenvolvido a partir de diversos ramos do conhecimento filosófico, histórico ou sociológico (RUDIGER, 1966 apud CAPARELLI e STUMPF, 2001).

O pensamento comunicacional se estabelece, no Brasil e em toda a América Latina, a partir da década de 70, com o reconhecimento e ampliação do Jornalismo que vinha se legitimando desde os anos 30 e que, efetivamente, passa a prevalecer nos anos 60 (FUENTES NAVARRO, 1992). Por essa ocasião, surgem os cursos de mestrado e doutorado em algumas universidades latino-americanas apresentando uma mescla de teorias e metodologias que cobriam desde aspectos da semiótica à psicanálise, de correntes pós-modernistas aos postulados neoliberais.

Observando a natureza do campo, Marques de Melo (2003, p.59) menciona que como objeto de estudo, a Comunicação tem sido alvo de interesse de inúmeras disciplinas científicas que a refletem teoricamente e a analisam empiricamente, a partir dos seus respectivos paradigmas. E completa, concordando com Miege (2000) que, como campo acadêmico, a sua identidade tem se caracterizado pelo delineamento de fronteiras estabelecidas em função dos suportes tecnológicos (mídia) que asseguram a difusão dos bens simbólicos e do universo populacional a que se destinam. Portanto, trata-se de um campo delimitado por duas variáveis: (a) a indústria midiática (formada pelas organizações manufatureiras ou distribuidoras de cultura) e (b) os serviços midiáticos (englobando as empresas terciárias, dedicadas ao planejamento, produção e avaliação de mensagens, dados e informações a serem difundidos pela mídia).

É nesse universo de discussão, produção, busca e consolidação de identidade que se instala a primeira associação de pesquisadores na área, a Intercom, que atuando desde dezembro de 1977 como associação científica, sempre exerceu papel histórico no sentido de incluir a Comunicação como área autônoma de conhecimento no sistema nacional de ciência e tecnologia do país e, ainda de sedimentar sua legitimação perante as agências nacionais e regionais de fomento científico.

Essas batalhas, aliadas às suas inúmeras atividades de publicação, divulgação e gerenciamento da produção da área, vêm fortalecendo sua condição de entidade aglutinadora do maior contingente nacional de pesquisadores vinculados aos distintos segmentos do campo comunicacional. Com intensa presença e marcante atuação da comunidade científica do país e do exterior, seus eventos (como oficinas, prêmios e concursos) resultam sistematicamente em uma expressiva quantidade e qualidade de publicações em diversificados suportes, formatos e gêneros.

Neste contexto, desde seu nascimento, esta associação tem envidado esforços no sentido de desenvolver mecanismos para a gestão, conservação e divulgação da memória técnica, científica e acadêmica produzida pela área. Para tanto, implementa em 1977 a Portcom, então Centro de Documentação em Comunicação e hoje Rede de Informação em Ciências da Comunicação dos Países de Língua Portuguesa.

Atualmente, a Portcom tem dupla função: (a) a primeira se refere ao desenvolvimento de metodologias adequadas para a criação, gerenciamento, fomento e divulgação de serviços de informação coordenados entre e com pesquisadores de vários países, por meio da consolidação da Federação de Bibliotecas Digitais em Ciências da Comunicação, e (b) a segunda se refere à implementação, no próprio âmbito da Intercom, de bibliotecas digitais seguindo suas próprias metodologias de modo a 
organizar, preservar e disseminar sua documentação produzida e derivada de suas várias interações e atividades e, ainda, servir de piloto para estudos de viabilidade e demonstração às instituições da área interessadas em integrar a Federação.

Um dos projetos que vem desenvolvendo é o Reposcom - Repositório Institucional da Intercom e da Portcom, implementado de maneira alinhada aos pressupostos dos movimentos OAI e OA, que serve como ferramenta de divulgação e compartilhamento da produção interna, dando-lhe visibilidade, garantindo sua acessibilidade e preservação digital, compartilhando conhecimento entre os pares, e ainda fornecendo indicador tangível da atuação das instituições envolvidas.

\section{O PROJETO REPOSCOM}

O Reposcom - Repositório Institucional da Intercom e da Portcom - teve seu inicio no final de 2003, a partir de uma parceria entre a Portcom, o Núcleo de Pesquisa Design de Sistemas Virtuais Centrado no Usuário da ECA-USP e o IBICT - Instituto Brasileiro de Informação em Ciência e Tecnologia ${ }^{11}$. Foi aberto ao público em 07 de setembro de 2004 durante as atividades do XIV ENDOCOM - Encontro Nacional de Informação em Ciências da Comunicação, evento componente do XVII Congresso Brasileiro de Ciências da Comunicação, promovido pela Intercom em Porto Alegre, RS.

Sua implementação abrangeu 5 etapas, descritas a seguir:

- $1^{\text {a }}$. etapa - Análise do ambiente de geração de conteúdo - Intercom e Portcom.

- $2^{\text {a }}$. etapa - Concepção estratégica do Repositório

- $3^{\text {a }}$. etapa - Desenvolvimento do modelo operacional

- $4^{\mathrm{a}}$. etapa - Desenvolvimento de estratégias de implementação do Repositório

- $5^{\text {a }}$ Etapa - Gestão do Repositório

\section{Análise do ambiente de geração de conteúdo - Primeira Etapa}

Um levantamento e análise da produção da Intercom evidenciaram a possibilidade de classificá-la de diversificadas formas, observando sua autoria e origem, tipologia, formato e suporte do material produzido, periodicidade, área temática e cobertura geográfica.

Em relação à autoria, encontram-se (a) publicações produzidas diretamente pela diretoria, conselho curador e sócios da entidade em suas atividades rotineiras e (b) publicações derivadas dos eventos, concursos e prêmios promovidos, sendo a maioria de autores diversos como pesquisadores, docentes, alunos de graduação e pósgraduação e profissionais de todas as regiões do país, como de outros países, que utilizam as atividades da Intercom para divulgar seus produtos e resultados e compartilhar experiências com os pares.

\footnotetext{
${ }^{11}$ Com o auxílio financeiro e técnico do IBICT a equipe da Portcom customizou a versão pioneira do software DSpace para o idioma português do Brasil. Versão essa que foi repassada para outras instituições do país, como por exemplo, o Supremo Tribunal de Justiça (STJ) que lança a BDJUR Biblioteca Digital Jurídica. Atualmente, o IBICT se responsabiliza oficialmente pela atualização constante da customização para o português brasileiro das novas edições do DSpace, bem como de sua distribuição aos interessados.
} 
Em termos de tipologia, essa produção envolve desde relatórios, manuais, normas, projetos, livros, revistas, fotos, vídeos, material promocional, folders, cartazes, jornais, anais de congresso, papers selecionados, palestras dentre outros. Com relação ao suporte encontram-se material impresso e eletrônico e quanto ao formato arquivos de áudio, imagem parada, imagem em movimento, texto e multimídia.

A Intercom produz, com periodicidade variada entre semanal, mensal, semestral, anual e bi-anual, imensa quantidade de eventos com cobertura local, regional, nacional, bi-nacional (por exemplo, com a França, México, Argentina, Canadá, EUA, Itália etc. ) e também colóquios internacionais. À guisa de ilustração vale comentar que somente o congresso anual da Intercom (que em 2007 terá a sua 30a . edição) tem em média a participação de quatro mil pessoas e apresentação de aproximadamente novecentos papers e mais de oitocentos projetos experimentais de alunos oriundos dos cursos de graduação brasileiros (jornalismo, relações públicas, publicidade e propaganda, editoração, cinema e vídeo, rádio e TV) .

Além dos eventos, ponto forte de suas atividades, a Intercom também promove concursos e prêmios com diferentes propósitos, periodicidades irregulares e para públicos que vão desde pessoas físicas (como alunos de graduação, graduados, alunos de cursos de especialização, mestrandos, doutorandos, professores, pesquisadores), até pessoas jurídicas (como núcleo de pesquisa inovador, instituições paradigmáticas, escolas de ensino de graduação e pós-graduação e empresas midiáticas). Tais concursos e prêmios geram também uma grande quantidade de publicações.

A análise meticulosa dessa produção evidenciou a existência de normas e manuais de procedimentos insuficientes para a formatação e edição das publicações produzidas pela Intercom, seja diretamente ou por meio de seus eventos e prêmios, acarretando a perda de informações importantes para o resgate da memória técnica e institucional.

\subsection{Concepção estratégica do Repositório - Segunda Etapa}

O projeto da Federação de Bibliotecas Digitais em Ciências da Comunicação teve seu modelo operacional alinhado ao movimento do acesso livre, uso do protocolo OAI, estruturação de provedores de dados e de serviços seguindo as premissas de autoarquivamento, acesso público e irrestrito, interoperabilidade com sistemas congêneres etc. O Reposcom é entendido como um módulo dessa Federação, ou seja, como uma biblioteca digital provedora de dados ${ }^{12}$, estruturando seu modelo operacional de maneira equivalente, conforme pode ser visualizado na Figura 1 abaixo.

\footnotetext{
12 Provedor de dados são entidades que implementam e gerenciam sistemas que mantém repositórios digitais e suportam o protocolo OAI/PMH como meio de expor seus metadados para serem coletados por provedores de serviços ou agregadores. Provedores de serviços implementam e gerenciam a ferramenta que coleta automaticamente os metadados expostos pelos provedores de dados, os organiza e oferece produtos e serviços de valor agregado ao usuário final via interface única de acesso (IBICT, s.d.)
} 


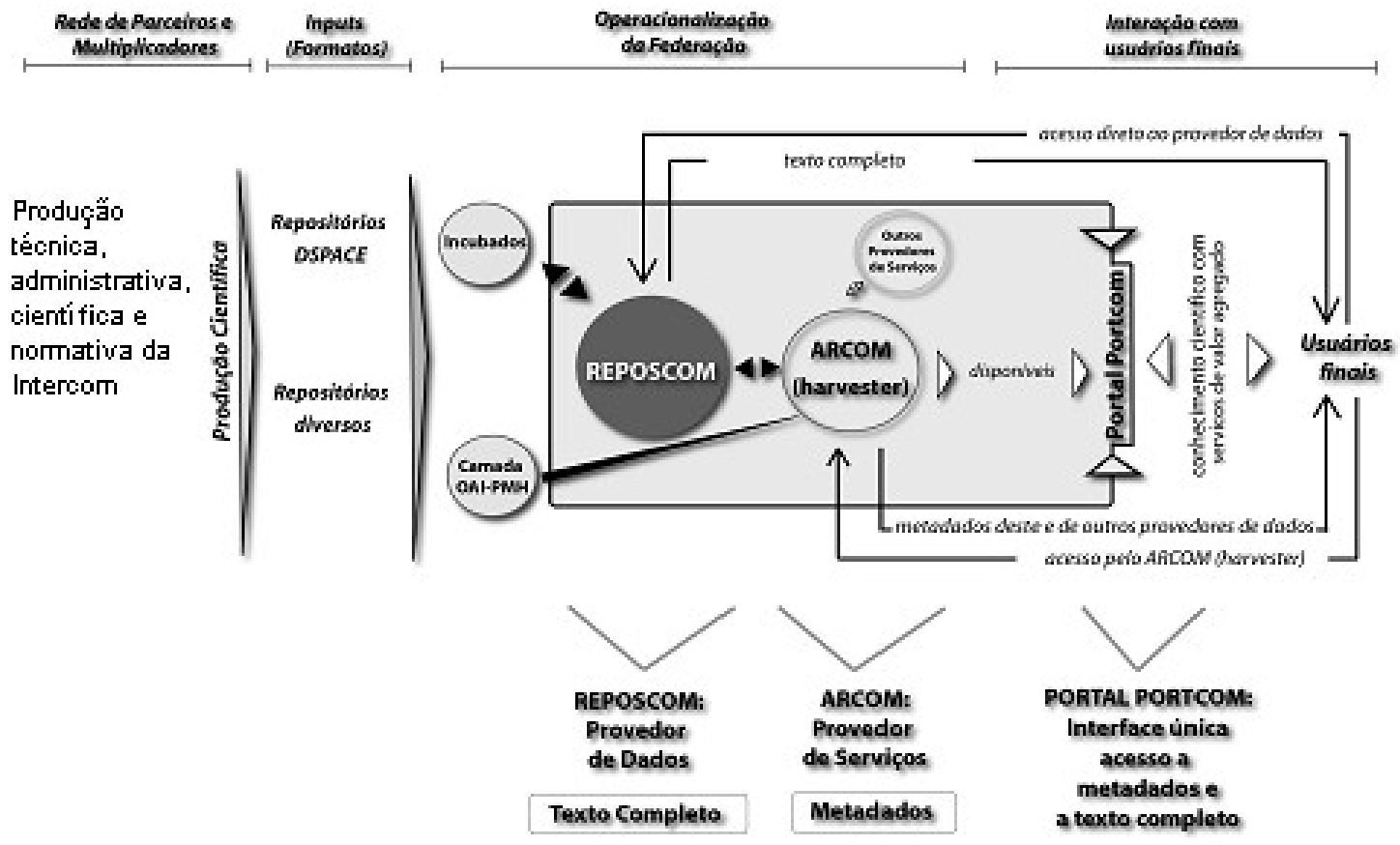

FONTE: FERREIRA, S.M.S.P. Federação de Bibliotecas Digitais em Ciências da Comunicação: um espaço de informação, aprendizado e interação. São Paulo, 2006. 217p. Tese [Livre-Docência]. Escola de Comunicações e Artes. Universidade de São Paulo.

Nesse modelo enfatiza-se o input de dados pautado nos produtos resultantes das várias atividades da Intercom junto à comunidade técnica, cientifica e acadêmica. Essa produção é armazenada e processada no repositório institucional (Reposcom) implementado com uso do protocolo OAI, o qual disponibiliza seus metadados para coleta pelo provedor de serviços em desenvolvimento pela Federação intitulado Arcom (ou qualquer outro harvester interessado, por exemplo o OÁSIS do Ibict $^{13}$ ), contribuindo para a oferta de busca integra, normalizada e articulada por meio de interface única de acesso.

Os objetivos traçados para o Reposcom foram:

- contribuir para aumentar o impacto da pesquisa produzida ou veiculada nos eventos e publicações da Intercom, ampliando sua visibilidade e acessibilidade;

- preservar a memória intelectual resultante da interação constante entre membros de comunidades locais, nacionais, regionais e internacionais facilitada pela Intercom.

- $\quad$ otimizar a gestão da informação técnica-científica produzida nas varias instancias da Intercom e seus núcleos de pesquisas.

- $\quad$ oferecer uma metodologia de fácil implementação e um mecanismo ágil para o armazenamento, a divulgação e o acesso à produção intelectual em texto completo (em formato estruturado ou não estruturado) passível de ser transferida para instituições parceiras que queira utilizá-la.

${ }^{13}$ Maiores informações: http://oasisbr.ibict.br/ 
Para tanto, o Reposcom consolida um conjunto de serviços com foco nas produções técnica, científica, administrativa, normativa e acadêmica geradas em todos as atividades que a Intercom promove, de modo a integrar, processar, preservar e compartilhar essa memória em um portal de acesso público e com interface de busca integrada. Observando ainda a especificidade da área, preocupa-se em integrar além dos diversos tipos de fontes de informação (relatórios, revistas, livros, trabalhos apresentados em eventos, vídeos, fotos, relatórios, material promocional etc), os conteúdos em diversificados suporte e formatos como: multimídia, programas de áudio, imagem parada, imagem em movimento, texto etc.

Frente a tais objetivos, define seu público alvo como sendo -

- os coordenadores de núcleo de pesquisa, eventos e prêmios em primeira instância e como pólo multiplicador, buscando incentivá-lo a participar do processo de organização da memória da produção gerada a partir de sua atuação.

- alunos, profissionais, docentes e pesquisadores em geral, autores de trabalhos apresentados nos eventos e/ou prêmios ou publicações da Intercom, e que necessitam de motivação e capacitação para atuar no auto-arquivamento de suas produções.

- editores das publicações produzidas diretamente pela Diretoria e Conselho Curador da Intercom, de modo a garantir sua normalização e produção garantindo assim inserção imediata no repositório.

No que se refere à política de conteúdo do repositório foi definido que qualquer documento gerado a partir da promoção e desenvolvimento dos eventos e prêmios da associação deve ser arquivado no repositório, incluindo aqui os materiais promocionais (como folders, cartazes, crachás certificados), os documentos administrativos (como relatórios técnico-científicos, prestação de contas e outros) e ainda os trabalhos apresentados, palestras, fotografias, jornais etc. Condições básicas são traçadas e perseguidas, visando dotar os documentos depositados de informações mínimas que os identifiquem, possibilitem seu reconhecimento e garantam sua autoria.

A definição da política de copyright, relacionada à propriedade intelectual e direito do autor foi tema de discussão junto à liderança da instituição, especificamente no que se refere aos trabalhos submetidos a seus eventos, pois nesse caso a autoria está vinculada a profissionais de diversas instituições nacionais e estrangeiras de ensino e pesquisa. Ações iniciadas em 2004, inicialmente no seio dos congressos nacionais e a partir de 2007 como parte de todos os eventos e prêmios da Intercom, garantem estatutos contendo cláusulas e normas regimentais com informações aos autores dos trabalhos sobre a atual política e alinhamento ao Movimento do Livre Acesso, e formalizando a concessão à Intercom/Portcom do direito, não exclusivo, de inserir os trabalhos submetidos aos diversos eventos no acervo do Reposcom, divulgando-os ampla, irrestrita e publicamente aos interessados.

Porém, políticas de acesso ao conteúdo dos documentos depositados levantaram outra série de definições. Muito embora o repositório seja de acesso livre para a maioria dos documentos depositados (em especial os de cunho científico e acadêmico), os de origem administrativa são de caráter restrito e devem ficar disponíveis apenas para grupos de usuários selecionados.

Dada a diversidade de tipologia e formatos dos documentos a serem inseridos no repositório, definições quanto ao tratamento mais adequado dos mesmos (digitalização versus OCR, PDF, XML etc.), dimensões e procedimentos (para vídeos, áudios e fotos, 
por exemplo) frente a questões específicas para armazenamento e preservação digital também foram delineadas.

\subsection{Desenvolvimento do modelo operacional - $3^{\mathrm{a}}$ Etapa}

Após uma avaliação das plataformas do tipo open source existentes para a constituição e gestão de RI, foi selecionada a plataforma DSpace $e^{14}$ para a implementação do REPOCOM. Trata-se de um sistema de fonte aberta desenvolvido pelo Massachusetts Institute of Technology (MIT) e pela Hewlett-Packard (HP), que tem como objetivos coletar, preservar, gerenciar e disseminar o produto intelectual de pesquisadores. É livremente distribuído às instituições de ensino superior e de pesquisa, podendo ser adaptado e expandido funcionalmente, nos termos da BSD Open Source License $e^{15}$.

Aceita todas as formas de materiais digitais (texto, imagem, vídeo e áudio), apresenta um workflow para coleta e descrição de documentos passível de ser adaptável a necessidades específicas e, ainda, tem uma forte preocupação com a preservação digital em longo prazo. Segundo Ferreira e Shintaku (2006), outras características importantes deste sistema são: (a) o recurso de auto-arquivamento que permite que os próprios autores façam a submissão de seus documentos; (b) workflow de validação das informações e metadados incluídos que oferece um controle sobre a qualidade e precisão dos dados; (c) sua disponibilidade na WEB via protocolo OAI garante, além da segurança, a indexação por especialistas internacionais; (d) a descrição dos metadados seguindo o padrão internacional Dublin Core $^{16}$ que permite o intercâmbio de informações com outros sistemas que utilizam o mesmo padrão; (e) a descentralização dos processos de alimentação, auto-arquivamento e recuperação que possibilita a criação de estruturas de rede e participação em ambientes federados; (f) sistema de gerenciamento compartilhado, distribuindo-se papéis e responsabilidades entre administradores e supervisores; (g) software livre e código fonte aberto permitindo a customização e desenvolvimento de novas ferramentas que podem ser agregadas ao sistema de acordo com as necessidades e especificidades do usuário.

Organiza seu conteúdo a partir dos conceitos de "Comunidades", "Coleções" e "Itens". Suas "comunidades", por exemplo, podem ser estruturadas de acordo com as áreas cobertas pelo repositório e podem conter uma infinidade de sub-comunidades e coleções. Os documentos (objetos) digitais denominados de "Itens" são agrupados em "Coleções" conforme os objetivos da Comunidade e do repositório. Tais conceitos podem ser visualizados com maior clareza na Figura 2.

\footnotetext{
${ }^{14}$ O DSpace está escrito em Java e é suportado por um conjunto de ferramentas open source, tais como, o PostgreSQL, o Tomcat e o Lucene (motor de pesquisa). Maiores informações -http ://www.DSpace.org/faqs /\#what.

${ }^{15}$ Maiores informações - http://www.hp.com

${ }^{16}$ Maiors informações: - http://www.dublincore.org
} 
Figura 2 - Representação esquemática dos conceitos de comunidade, sub-comunidade e coleções do

software DSpace

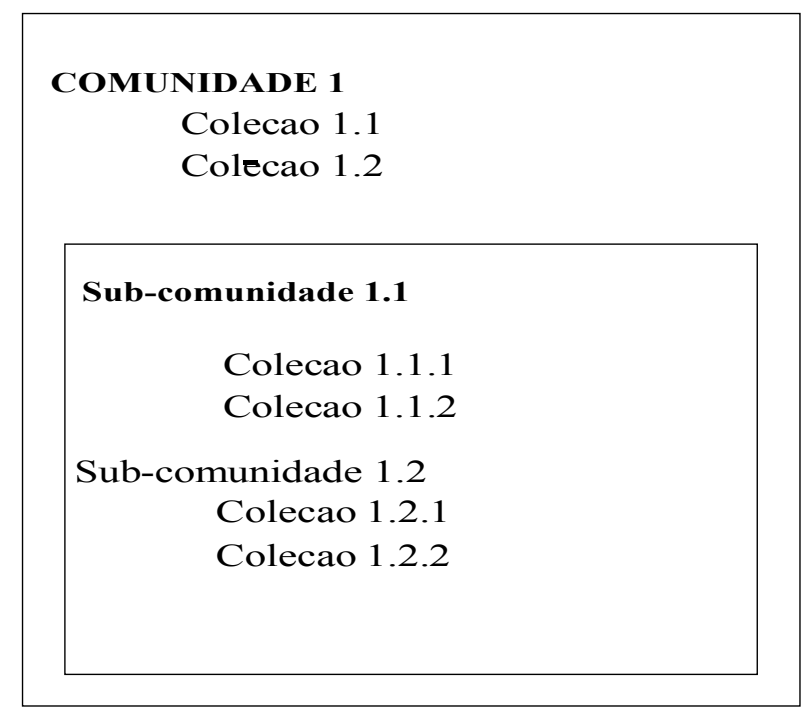

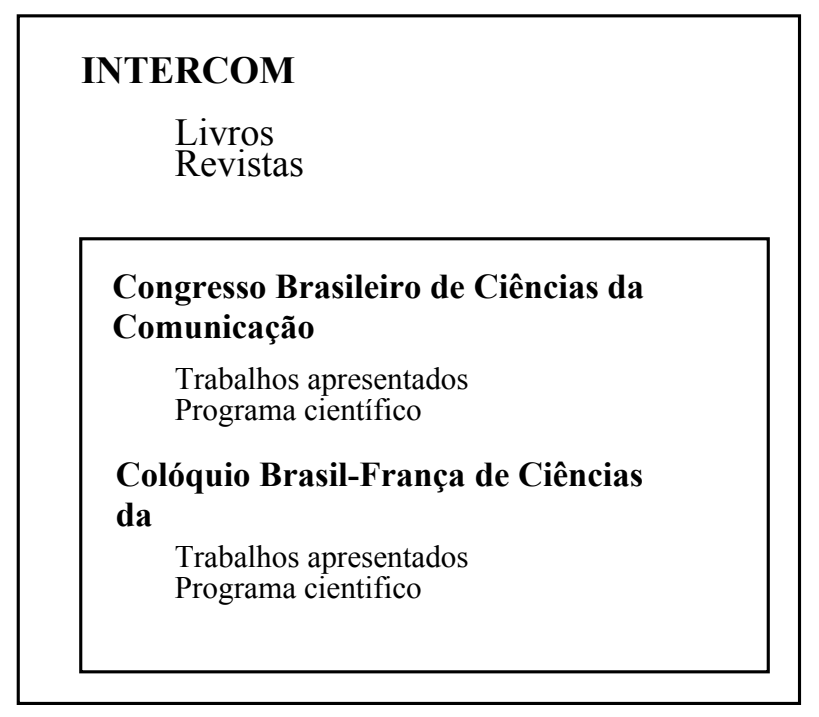

No projeto Reposcom optou-se por categorizar as comunidades como sendo a instituição superior e macro que o repositório representa, portanto, tem-se duas comunidades: Intercom e Portcom. Porém, como parte da atuação enquanto "incubadora de iniciativas" que o projeto da Federação da Portcom oferece às instituições parceiras, pode ocorrer o aparecimento de outras comunidades. Essas instituições parceiras, durante prazo determinando e acordo assinado, podem utilizar o Reposcom para incluir seus conteúdos, analisar o uso do software, capacitar sua equipe e, ao mesmo, ter um tempo para consolidar e fortalecer a infra-estrutura adequada em sua instituição para implementação de seu próprio repositório ${ }^{17}$.

As sub-comunidades estão sendo entendidas como cada um dos eventos (congressos, prêmios e concursos) promovidos sistematicamente pela Intercom, possibilitando desse modo a organização de documentos por temática (quando se tratar de eventos temáticos) e por espaço geográfico (quando se trata de eventos bi-nacionais ou regionais).

As coleções serão sempre criadas em decorrência da tipologia das fontes de informação produzidas e elas deverão estar vinculadas tanto às comunidades como às

\footnotetext{
${ }^{17}$ Desde início de 2006, existem duas outras comunidades já vinculadas ao Reposcom - a primeira se refere à comunidade criada para o Núcleo de Pesquisa em Comunicação Organizacional e Relações Públicas - Nupcorp da USP contendo bibliografia da produção brasileira da área identificada e indexada pela equipe coordenada pela Profa. Dra. Margarida Kunsch. A segunda comunidade parceira do Reposcom é a dos Programas Brasileiros de Pós-graduação em Ciências da Comunicação, a qual disponibiliza resumo de todas as teses e dissertações defendidas no país e que foram levantadas e indexadas pelo Núcleo de Pesquisa em Informação, Tecnologias e Práticas Sociais da UFRGS, coordenado pela Profa. Dra. Ida R. C. Stumpf.
} 
sub-comunidades. Portanto, as coleções da comunidade Intercom serão intituladas revistas, livros, jornal intercom, normas e outras Ou seja, correspondem aos tipos de fontes de informação editado pela sociedade. Já as coleções das sub-comunidades de eventos ou prêmios serão relatórios, trabalhos apresentados, material promocional, fotos, vídeos dentre outros, portanto, fontes de informação geradas em decorrência de um evento ou prêmio específico. Cada coleção será composta de $n$ itens, objetos ou documentos, correspondendo a quantidade de documentos registrados em cada coleção, os quais serão indexados seguindo os padrões já pré-estabelecidos de metadados do próprio software pautado no Dublin Core.

As coleções, em sua maioria, são de acesso público e contém o texto na íntegra, porém aquelas de caráter administrativo (por exemplo, os relatórios de prestação de contas, por exemplo), são implementadas com restrições de acesso. Embora a maioria das coleções remeta ao texto completo, em alguns casos apenas o resumo ou a imagem da publicação é disponibilizado. Isso ocorre, principalmente, com documentos muito antigos e que já não estão mais disponíveis, mas que foram referendados no sistema como forma de manter o registro e preservar a memória. As descrições dos metadados de cada coleção foram estudadas e definidas a priori, respeitando-se suas especificidades, procedência, formato e suporte. Porém, adequando-as a proposta já existente no sofwtare DSpace, de modo a garantir a facilidade nos momentos de atualização (upgrade) do próprio sistema. A única adaptação feita foi na camada da interface, visualização ao usuário depositando, de modo a agilizar sua atividade e a facilitar sua compreensão.

O tratamento dos documentos a serem depositados vem merecendo também estudos específicos, em especial no que se refere à normalização dos documentos mais antigos, inclusão de informações mínimas de identificação e tratamento do suporte visando migrar para o meio eletrônico.

\subsection{Desenvolvimento de estratégias de implementação do Repositório - $4^{\mathrm{a}}$ Etapa}

A customização do DSpace para o português foi iniciada com a versão $1.1 .1 \mathrm{em}$ 2003 pela equipe da Portcom com apoio do IBICT. Em setembro de 2004, quando o Reposcom é lançado pela primeira vez, já estava sendo utilizada a versão 1.2 .

A segunda edição do Reposcom é colocada on-line em final de 2005 já com a versão 1.3.1 do software DSpace. Hoje, no seu terceiro ano de existência, o Reposcom está novamente migrando para a versão 1.4 a qual incorpora novidades na interface e, em especial, nos serviços de disseminação seletiva de informação, estatística de uso e introdução de novos idiomas para tradução da interface.

A primeira alimentação do sistema, quando na versão 1.3 .1 foi feita com a importação dos dados disponíveis na antiga base de dados Portdata, desenvolvida em MicroIsis, que continha indexação de algumas publicações da Intercom. Desse modo, quando o repositório é lançado, em setembro de 2004, já contava com o registro de cerca de 2000 itens, porém grande parte deles ainda sem texto completo. 
Figura 3 - Sub-Comunidades e Coleções da Comunidade Intercom do Reposcom

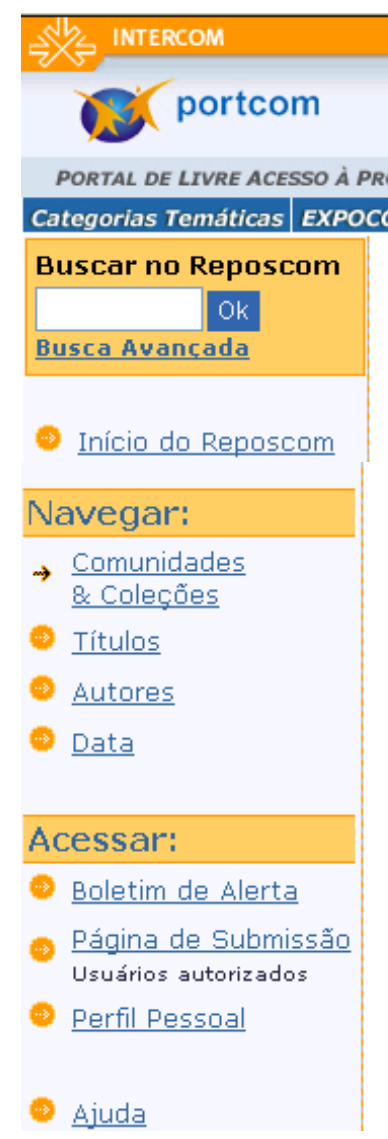

\section{Comunidades e Coleções}

Abaixo está uma lista de Comunidades e suas respectivas Coleções. Clique em qualquer uma para conhecê-la

\section{Intercom - Sociedade Brasileira de Estudos \\ Interdisciplinares da Comunicação}

Livros [8]

Outros [106]

\section{Colóquio Brasil - França de Ciências da \\ Comunicação \\ Trabalhos apresentados-Colóquio Brasil - França de Ciências da Comunicaçẵa [26] \\ Colóquio Brasil-Canadá \\ Trabalhos apresentados - Colóquio Brasil-Canadá [11] \\ Colóquio Brasil-Estados Unidos em Ciências da Comunicacão}

Atualmente, conta com cerca de 10.000 itens, sendo que desses aproximadamente $60 \%$ se referem a textos completos e representam a coleção de trabalhos apresentados nos congressos nacionais e bi-nacionais, desde 2002. Para o $30^{\circ}$ aniversário do congresso anual, a ocorrer em setembro de 2007, estão sendo inseridos os livros programa, as fotos e os materiais promocionais produzidos em todos os eventos nacionais anteriores. Certamente, a organização dessa memória retrospectiva e sua disseminação à comunidade poderão suscitar relevantes estudos sobre a evolução da área tanto em termos dos temas, tópicos discutidos e trabalhos apresentados desde sua origem, como em relação à evolução dos próprios produtos promocionais enquanto representações do trabalho de publicitários e editores.

A inserção dos conteúdos foi definida estrategicamente em função do maior interesse da comunidade. Portanto, iniciou-se a atividade de alimentação com os trabalhos apresentados nos congressos e prêmios. Os demais eventos regionais, locais e binacionais, seguiram esse fluxo também. Posteriormente, incluir-se-ão os respectivos programas científicos, fotos, relatórios técnicos, materiais de divulgação e outros. Finalmente, serão inseridos os conteúdos gerados diretamente pela Diretoria da Intercom, como livros, revistas, relatórios, normas e arquivo técnico-científico.

Uma das estratégias para agilizar o processo de inserção e tratamento dos trabalhos (papers) apresentados nos diversos eventos foi a implementação, na Intercom, de um sistema de gerenciamento de eventos para, além de atuar na inscrição on-line, também centralizar o processo de submissão e avaliação dos trabalhos. Por meio desse 
sistema, os congressistas autodepositam seus trabalhos preenchendo os metadados padronizados além de serem direcionados a tratar e formatar seus documentos seguindo padrões e normas definidos detalhadamente. Essa automação iniciada apenas com os congressos nacionais, a partir de 2007, se replica a todos os eventos da Intercom.

Esse sistema está fortalecendo habilidades de auto-arquivamento nos participantes, melhorando o processo de identificação dos trabalhos tendo em vista que a maioria já se atenta às normas prescritas, formalizando a revisão pelos pares e garantindo os direitos autorais e o acesso público aos textos gerados. Desse modo, o próximo passo é o desenvolvimento de aplicativos que possibilitem importar, de forma automática, todos os trabalhos inseridos no sistema de eventos para o Reposcom. A inclusão dos demais documentos produzidos no evento (como fotos, materiais promocionais, vídeos, relatórios, programa etc) é feita manualmente, tanto pela equipe do Portcom como pela secretaria da Intercom, seguindo o workflow disponível na íntegra.

Foram ainda projetadas várias estratégias para a divulgação do Repositório e respectivas sub-comunidades e coleções junto aos coordenadores dos prêmios e eventos, à diretoria da associação e sua equipe de funcionários e à comunidade em geral, visando incentivar a adoção, participação e cooperação. Tais ações foram desenvolvidas no âmbito da própria Intercom, a partir da análise dos aspectos culturais, sociais, políticos e de gestão envolvidos, entre elas podem ser citadas:

(a) a atuação sistemática junto à Diretoria da associação, coordenadores de eventos e comunidade em geral para adoção do formato padrão mínimo de apresentação de documentos, garantindo a qualidade dos dados, a descrição correta dos textos e sua adequada identificação.

(b) o desenvolvimento do sistema de gerenciamento de eventos pautado, não somente no auto-arquivamento, como no uso do formato padrão e metadados compatíveis visando sua interoperabilidade e integração com o repositório institucional.

(c) cadastramento do repositório em mecanismos de coleta (harvester) nacional e internacional aumentando sua visibilidade e acessibilidade, garantindo indiretamente aos autores maior reconhecimento e prestígio. Atualmente, o Reposcom está sendo coletado pelo Google e Google Scholar, pelo OASIS do IBICT e já se encontra devidamente cadastrado no DOAR - Directory of Open Access Repositories ${ }^{18}$, no ROAR - Registry of Open Access Repositories ${ }^{19}$ e no Celestial Registered Archives ${ }^{20}$.

(d) a estratégia de convencimento junto aos coordenadores de núcleos de pesquisa e de eventos da Intercom para que eles mesmos se encarreguem de auto-depositar o material produzido por sua equipe, ainda vem sendo trabalhada, mas já se tem registro do crescente uso e procura do repositório por pesquisadores e alunos para consulta, pesquisas, estudos bibliométricos, avaliação de desempenho etc.

(e) o acompanhamento sistemático dos estudos e melhorias feitas no software por outras equipes técnicas, bem como divulgação do que tem sido feito no Reposcom, é fundamental para a manutenção da atualidade do mesmo, sua inserção no mercado e crescimento constante.

\footnotetext{
${ }^{18}$ Maiores informações - http://www.opendoar.org/

${ }^{19}$ Maiores informações - http://roar.eprints.org/

${ }^{20}$ Maiores informações - http://celestial.eprints.org/
} 


\subsection{Gestão do Reposcom - $5^{\text {a }}$ Etapa}

Após a implementação e divulgação do repositório, dever-se-ia passar para a etapa da manutenção e gestão do repositório, entrando em um processo de fluxo contínuo de inserção de novos conteúdos. Porém, não se pode dizer que já se está nesse processo, pois ainda se tem uma convergência na principal atividade - tanto com a inclusão dos produtos e publicações retrospectivas da Intercom (e respectiva identificação, tratamento, digitalização etc.) como com a inserção dos eventos em desenvolvimento.

A principal estratégia de gestão que se tem levado a cabo, é a organização anual de encontros entre a comunidade de pesquisadores, docentes, alunos e editores de revistas científicas tanto da área de comunicação e da ciência da informação. A discussão periódica entre interessados nas questões voltadas à gestão da informação e comunicação científica tem suscitado melhorias constantes no desenvolvimento das atividades tanto do projeto Reposcom como da própria Portcom. Dentre tais encontros, podem-se ser citados o ENDOCOM - Encontro de Informação em Ciências da Comunicação (que em 2007 terá sua 17 edição) e o LUSOREVOM - Encontro de Editores de Revistas Científicas em Ciências da Comunicação (que esse ano terá sua $2^{\text {a }}$. edição).

\section{CONSIDERAÇÕES FINAIS}

Iniciativas como a do Reposcom, alinhadas aos movimentos OAI e OA, estão gerando impacto significativo nos sistemas de informação em Ciência e Tecnologia (C\&T), com conseqüências importantes nos setores educacionais, editorial, nas comunidades acadêmicas e também nas bibliotecas e centros de informação. Deve-se salientar que um serviço dessa natureza, sendo oferecido no seio de uma sociedade, é um retorno intencional aos primórdios da comunicação científica quando os pesquisadores detinham o controle dos rumos da produção e, conseqüentemente, da ciência.

Por outro lado, a participação do Reposcom no desenvolvimento da área de comunicação é inegável. Esse projeto está introduzindo paulatinamente e de maneira precisa e qualificada, a comunidade científica que gravita gira em torno das atividades da Intercom, no atual contexto informacional internacional agregando-lhe valores que aumentam a visibilidade de sua produção de forma coletiva e integrada.

Enquanto ponto de sustentação para o desenvolvimento de competências informacionais da comunidade da área, melhorias têm sido percebidas ano a ano nos participantes e coordenadores dos eventos e prêmios da Intercom. Melhorias essas que refletem o amadurecimento da área, sua preparação para o uso mais adequado dos produtos e serviços de informação, sua compreensão mais completa do processo de comunicação científica e geração de publicações adequadamente normalizadas e produzidas. Tudo isso se reflete na qualidade das informações veiculadas nos eventos da área e, obviamente, no crescimento e fortalecimento da área de comunicação no Brasil e no mundo.

Assim, esse repositório tem conseguido crescer paulatinamente em termos de número de registros, uso e acesso pela comunidade acompanhando o ritmo acelerado de produção da área, aumentando consideravelmente a visibilidade especificamente de conteúdos produzidos em eventos, que é ainda, notadamente, o produto mais procurado pela comunidade desta área. O Reposcom cumpre assim um papel fundamental no 
desenvolvimento da área, divulgação de novas idéias, controle bibliográfico e memória técnica.

Como proposta de futuro, o Reposcom, além da inclusão de toda a produção retrospectiva da Intercom e sistematização do fluxo para inserção automática da produção atual, prevê ainda a disponibilizarão de novas funcionalidades de pesquisa interagindo com outros repositórios da área e, principalmente, com os demais serviços oferecidos pela Portcom no projeto da Federação, melhoria de sua interface de acesso, ferramentas mais adequadas de estatística, controle das tabelas de autoridade e inclusão de vocabulário controlado na área.

\section{REFERÊNCIAS}

ARELLANO, M.; FERREIRA, S.M.S.P.; CAREGNATO, S. Editoração eletrônica de revistas científicas com suporte do protocolo OAI. In: FERREIRA, S.M.S.P., TARGINO, M.G. Preparação de revistas científicas: teoria e prática. São Paulo: Reichman, 2005. p.195-229.

BISHOP, A.P., VAN HOUSE, A., BUTTENFIELD, B.P. Digital Library Use: social practice in design and evaluation. MIT Press, 2003.

BOAI. BUDAPESTE Open Acess Initiative. 2002. URL://http://www.soros.org/openaccess/ read.shtml) Acessado em Dezembro, 2004.

CAPPARELLI, S.; STUMPF, I. R. C. El campo académico de la Comunicación. In: Maria Imaculada Lopes; Raúl Fuentes Navarro. (Org.). Comunicación: campo y objeto de estudio. Jalisco: Instituto Tecnológico y de Estudios Superiores de Ocidente, 2001, v. 1, p. 59-73.

CROW, R. The Case for Institutional Repositories: A SPARC Position Paper. Washington: The Scholarly Publishing \& Academic Resources Coalition, 2002. Available: http: //www.arl.org/sparc

FERREIRA, S.M.S.P. Federação de Bibliotecas Digitais em Ciências da Comunicação: um espaço de informação, aprendizado e interação. São Paulo, 2006. 217p. Tese [Livre-Docência]. Escola de Comunicações e Artes. Universidade de São Paulo.

FERREIRA, S.M.S.P., SHINTAKU, M. Workshop sobre software DSpace. In. Anais. Conferencia Iberoamericana de Publicações Eletrônicas no Contexto da Comunicação Cientifica. Brasília, UnB, 2006.

FERREIRA, S.M.S.P.; SOUTO, P. C. N. Federação de bibliotecas digitais lusófonas em ciências da comunicação. In: MARCONDES, C. H. et al. Bibliotecas digitais: saberes e práticas. Salvador/Brasília: UFBA/IBICT, 2005. p. 325-342.

FERREIRA, S.M.S.P.; SOUTO, L. Dos Sistemas de Informação Federados à Federação de Bibliotecas Digitais. Rev. Bras. Biblioteconomia e Documentação, v.2, n.1.

Disponível

em 
http://143.106.108.58/seer/ojs/ojs/viewarticle.php?id=17\&layout=abstract.

julho 2006.

FUENTES NAVARRO, R. Investigación sobre comunicación en México: los retos de la institucionalización. In: OROZCO, G. (coord) La investigación de la comunicación en México: tendencias y perspectivas para los noventas. México: Universidad Iberoamericana, 1992. p.11-38. (Cuadernos de Comunicación y Prácticas Sociales, 3).

GONÇALVES, M.; FRANCE, R.K.; FOX, E. MARIAN: flexible interoperability for Federated Digital Libraries. Computer Science, v.2163, Proceedings of the 5th European Conference on Research and Advanced Technology for Digital Libraries, 2001. p.173-186.

HARLEY, D. et all. Use and users of digital resources: a focus on undergraduate education in the Humanities and Social Sciences. Berkely, Center for Studies in Higher Education (CSHE), University of California, 2006. Available: http://digitalresourcestudy.Berkeley.edu/

IBICT (s.d.). Glossário BDTD. Disponível em http://bdtd.ibict.br/bdtd/glossario/ glossario.jsp. Acessado em 20 de março de 2005.

LYNCH, C.A. Institutional Repositories: Essential Infraestructure for Scholarship in the Digital Age. $A R L$, n.226, p. 1-7, Feb 2003. http://www.arl.org/newsltr/226/ir.html

MARQUES DE MELO, J. História do pensamento comunicacional: cenários e personagens. São Paulo: Paulus, 2003.

MIÈGE, B. O pensamento comunicacional. Trad. de Guilherme João de Freitas Teixeira. Petrópolis, RJ: Vozes, 2000.

PINHEIROS, L.V.R. O desafio da formação profissional: da biblioteca às bibliotecas digitais. In: INTEGRAR - CONGRESSO INTERNACIONAL DE ARQUIVOS, BIBLIOTECAS, CENTROS DE DOCUMENTACAO E MUSEUS, 1., 2002. São Paulo. Anais... São Paulo: Imprensa Oficial, 2002. p.387-418.

PIRRI, M., PETTENATI, M.C., GIULI, D. Design of a Federation Service for Digital Libraries: the case of Historical Archives in the PORTA EUROPA Portal (PEP) Pilot Project. Proccedings. Int. Conf. on Dublin Core and Metadata for e-Communities, University of Florence, 2002.

RODRIGUES, E. et all. RepositóriUM: criação e desenvolvimento do Repositório Institucional da Universidade do Minho. In: Congresso Nacional de Bibliotecários, Arquivistas e Documentalistas, Estoril, Portugal, 2004. Disponivel: http://eprints.rclis.org/archive/00007962/fullmetadata.html. 
SENA, N.K. Open archives: caminho alternativo para a comunicação científica. Ciencia da Informação, Brasília, v.29, n.3, p.71-78, set/dez. 2000. Disponivel: http://www.ibixt.br/cionline/290300/2930007.pdf. Acesso em 03.mar.2002.

SWAN, A.; BROWN, S. Open access self-archiving: an author study. Southampton: 2005. [An author study, Technical Report] Available: http://www.keyperspectives.co.uk/openaccessarchive/reports/Open $\% 20$ Access $\% 20 I I \% 2$ 0(author $\% 20$ survey $\% 20$ on $\% 20$ self $\% 20$ archiving) $\% 202005$.pdf\#search $=\% 220$ pen $\% 20$ Access $\% 20$ self-archiving $\% 3 \mathrm{~A} \% 20 \mathrm{an} \% 20$ author $\% 20$ study $\% 22$. Acesso em marco 2006.

WEITZEL, S. O papel dos repositórios institucionais e temáticos na estrutura da produção científica. Revista Em Questão, v.12, n.1, 2006. http://www6.ufrgs.br/seeremquestao/ojs/viewissue.php?id=7\#Artigos

\begin{abstract}
Considering the conceptualization, characterization and context of the institutional repositories (IR) this paper discuss the procedures, policies and strategies delineated to the implementation of IR in a research environment. The object of discussion is the project called Reposcom - Institutional Repository of Intercom (Brazilian Society of Interdisciplinary Studies of Communication) - which is part of a broader project managed by the Portcom - Information Network in Communication Sciences of Countries of Portuguese Language - and called Digital Libraries Federation in the Communication Sciences. Aiming to share the knowledge and experience acquired with the implementation of the Reposcom, this paper describes its work activities, the decisions made, the customization of the software DSpace (the technological solution) and the initial results achieved with the project.
\end{abstract}

KEYWORDS: Institucional Repositories. Software DSpace. Digital Libraries Federation. Communication Science. Scientific communication. Open Access Initiative.

Originais recebidos em: 15/03/2007

Texto aprovado em 15/06/2007 